\title{
Clinical implications of donor age: A single-institution analysis spanning 3 decades
}

\author{
Christopher T. Holley, MD, ${ }^{a}$ Rosemary F. Kelly, MD, ${ }^{b}$ Sara J. Shumway, MD, ${ }^{b}$ Roland Z. Brown, BS, \\ Marshall I. Hertz, MD, ${ }^{\mathrm{d}}$ Kyle D. Rudser, PhD, ${ }^{\mathrm{c}}$ Coco W. Quinlan, ${ }^{\mathrm{b}}$ Irena Cich, ${ }^{\mathrm{e}}$ and Gabriel Loor, MD
}

\section{ABSTRACT}

Background: We sought to clarify the effect of donor age as a continuous variable on morbidity and mortality in a single-institution experience.

Methods: From 1986 to 2016, 882 adult lung transplants were performed, including 396 in the lung allocation score era. Kaplan-Meier curves and Cox proportional hazards models were used to evaluate the association of donor age with overall survival and bronchiolitis obliterans syndrome (BOS) score $\geq 1$-free survival. Logistic regression was used to evaluate the association with primary graft dysfunction grade 3 . Natural cubic splines were used to explore donor age in a continuous fashion to allow for nonlinear relationships.

Results: In the lung allocation score era, unadjusted 5-year survival was not significantly different between 3 a priori-defined donor age groups: age $<40$, 40 to 54 , and age $\geq 55$ years $(64 \%, 61 \%$, and $69 \%, P=.8)$. Unadjusted 5 -year freedom from BOS $\geq 1$ was not significantly different $(34 \%, 20 \%$, and $33 \%$, respectively, $P=.1$ ). After we adjusted for comorbidities, cubic spline analysis demonstrated no effect between donor age as a continuous variable and hazard for mortality at 5 years. Similarly, no interaction was seen between donor age and risk of BOS or primary graft dysfunction 3. Adjusted analysis of all 882 transplants pre- and postinception of the lung allocation score also showed no effect of age on 10-year survival.

Conclusions: Long-term survival of lung transplant recipients was not affected by the age of the donor. These findings support the notion that donor age could be relaxed. (J Thorac Cardiovasc Surg 2017;154:2126-33)

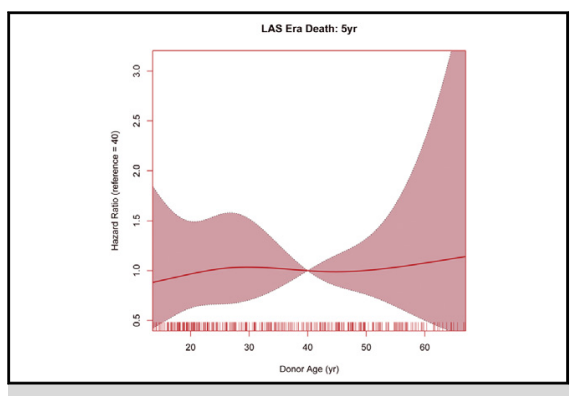

Adjusted natural cubic spline curve showing effect of donor age on survival.

\section{Central Message}

The age of the lung donor does not affect longterm survival. Consideration of older age donors may be reasonable and warranted.

\section{Perspective}

In this large, single-center study, donor age had no significant effect on long-term survival or lung function across a range of donor ages. The use of an older donor may be preferable to remaining on the waiting list, especially in patients with a poor life expectancy.

See Editorial Commentary page 2134.

See Editorial page 2124.
In many patients with end-stage lung disease, lung transplantation offers the only potential life-saving therapy; however, there remains a sizeable mismatch between the number of suitable donor lungs and potential recipients. ${ }^{1}$ The use

\footnotetext{
From the Departments of a Surgery and ${ }^{\mathrm{c}}$ Biostatistics, ${ }^{\mathrm{b}}$ Division of Cardiovascular and Thoracic Surgery, Department of Surgery, and ${ }^{\mathrm{d}}$ Division of Pulmonary, Allergy, Critical Care, and Sleep Medicine, Department of Medicine, University of Minnesota; and ${ }^{\mathrm{e}}$ University of Minnesota Medical School, Minneapolis, Minn.

Contributions by Drs Brown and Rudset were supported in part by award UL1TR0001114 from the National Center for Advancing Translational Sciences. Received for publication Aug 21, 2016; revisions received May 10, 2017; accepted for publication June 7, 2017; available ahead of print July 13, 2017.

Address for reprints: Gabriel Loor, MD, Division of Cardiothoracic Transplantation and Circulatory Support, Michael E. DeBakey Department of Surgery, One Baylor Plaza MS: BCM390, Houston, TX 77030 (E-mail: Gabriel.Loor@bcm.edu). 0022-5223/\$36.00

Copyright (c) 2017 by The American Association for Thoracic Surgery http://dx.doi.org/10.1016/j.jtcvs.2017.06.029
}

of older donors in particular remains a matter of great interest because it offers the potential for expanding the donor pool.

Recently, the notion of the inferiority of advanced age donor lungs has been called into question. ${ }^{2-5}$ Despite this, current international guidelines still state that the ideal lung donor is younger than 55 years old, ${ }^{6}$ and in 2011 less than 1 in 1000 lungs offered from donors older than 55 years of age were accepted for transplantation, compared with 12 in 1000 for lungs offered from donors 15 to 35 years of age.

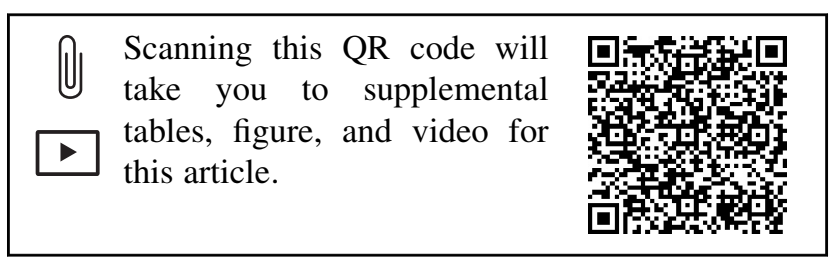




\section{Abbreviations and Acronyms \\ Alpha1 = alpha-1 anti-trypsin deficiency \\ BOS = bronchiolitis obliterans syndrome \\ $\mathrm{CI}=$ confidence interval \\ COPD $=$ chronic obstructive pulmonary disease \\ HR = hazard ratio \\ ICU = intensive care unit \\ IPF = idiopathic pulmonary fibrosis \\ LAS = lung allocation score \\ PGD = primary graft dysfunction \\ UNOS $=$ United Network of Organ Sharing}

A review of the United Network of Organ Sharing (UNOS) database in 2013 demonstrated that $<1 \%$ of all lung transplants were from donors older than 65 and $<10 \%$ of all lung transplants were from donors older than 55 years. ${ }^{5}$ Concerns about decreased elasticity, long-term environmental exposure, and malignancy risk often discourage acceptance of lungs from older donors. Conversely, lungs from younger donors are given greater consideration and leeway due to a perception of greater resilience and recovery potential. The current study evaluates the effect of donor age as a continuous variable on recipient outcomes in a large single center study.

\section{MATERIALS AND METHODS Study Design}

This was a single-center retrospective analysis of the Transplant Information Services database, a prospective database incorporating donor and recipient variables and outcomes for all lung transplants at the University of Minnesota from 1986 to 2016. Our study was approved by the institutional review board, which waived the need for consent from individual patients.

\section{Outcomes}

Transplant Information Services prospectively collects outcomes data for all transplants at the University of Minnesota. Certain outcomes, such as bronchiolitis obliterans score (BOS), were only available in the lung allocation score (LAS) era. For the purposes of this study, peak primary graft dysfunction (PGD) scores were defined according to the International Society for Heart \& Lung Transplantation PGD working group report by Christie and colleagues. ${ }^{7}$ Within the first 72 hours postoperatively we retrospectively recorded the partial pressure of oxygen and fraction of inspired oxygen for all patients in the LAS era using the lowest observed partial pressure of oxygen/fraction of inspired oxygen ratios at the specified time points, as well as a review of chest radiographs by an observer blinded to the donor age, to determine the PGD scores. The primary outcome was overall survival, with secondary outcomes including peak PGD3, BOS, and acute rejection. For donors older than age 50 years, a noncontrast computed tomography scan of the chest was used to rule out malignancy and evaluate for any emphysematous changes in the donor lungs, and echocardiography or right heart catheterization was used to rule out pulmonary hypertension.

\section{Statistical Analysis}

Descriptive statistics were tabulated overall and by a priori-defined donor age groups. These included the mean and standard deviation for continuous variables and frequency with percentage for categorical variables. Unadjusted survival curves were based on Kaplan-Meier estimates, whereas adjusted analyses used Cox proportional hazards regression models. Survival analyses included endpoints of overall survival and BOS-free survival (composite endpoint of BOS $\geq 1$ and death) up to 5 years posttransplant for the LAS cohort and 10 years for the entire cohort (pre-LAS and LAS combined). Adjusted odds ratios were estimated by the use of logistic regression. Robust variance estimation was used for confidence intervals (CIs) and $P$ values. Quantile regression used the Barrodale and Roberts algorithm for L1-regression, with CIs based on inversion of a rank test.

In an effort to magnify important relationships that might otherwise be missed across a spectrum of donor ages, we used natural cubic splines in our regression models. Traditional regression methods assume that the donor age effect on the outcome is uniform across donor age. For example, it assumes that a 10-year increase in donor age would be associated with the same effect on the recipient outcome if a donor aged 20 years old was compared with a 30 -year-old donor, as it would if a 50-year-old donor was compared with a 60-year-old donor. In our case, the use of splines relaxed any particular assumption of the relationship between donor age and outcomes. For example, the effect of a 10-year increase in donor age on recipient outcomes was allowed to be different for donors aged 20 years compared with donors aged 50 years.

The adjusted analysis in the LAS era considered LAS, estimated glomerular filtration rate $<60 \mathrm{~mL} / \mathrm{min} / 1.73 \mathrm{~m}^{2}$, donor age, laterality (single vs bilateral), sex, recipient age, wait-list time, and primary disease (categories of chronic obstructive pulmonary disease [COPD]/alpha-1 anti-trypsin deficiency [alpha1], cystic fibrosis, idiopathic pulmonary fibrosis [IPF]/interstitial lung disease, and other). Body mass index, mean pulmonary artery blood pressure, and ischemic times had too many missing values for inclusion in the model. Analyses of the entire cohort was performed to explore findings from the LAS era and to provide longer follow-up. Although this analysis included the effect of the LAS era, the actual LAS, as well as estimated glomerular filtration rate, were not included in the analysis because of missing data points in the pre-LAS cohort.

All analyses were conducted using R v3.1.1 (R Core Team 2014, Vienna, Austria) and the RMS library v4.2-1 (Vanderbilt Department of Biostatistics, Vanderbilt University, Nashville, Tenn).

\section{RESULTS}

\section{Patient Characteristics (LAS Era)}

A total of 396 transplants at the University of Minnesota were analyzed in the LAS era, which started in May 2005. The 3 donor age groups $(<40,40-54$, and $\geq 55$ years) exhibited similar characteristics with the exception of differences in donor sex, primary disease, and recipient age at transplant (Table 1). Recipients receiving lungs from older age donors ( $>55$ years old) were older than those receiving lungs from younger donors. They were also more likely to have COPD/alpha 1 and less likely to have cystic fibrosis, IPF, or other primary diagnoses.

\section{Unadjusted Outcomes (LAS Era)}

Unadjusted survival did not differ significantly between donor age categories: survival rates at 1 year for donors $<40,40-54$, and $\geq 55$ years old were $87 \%, 87 \%$, and $90 \%$ respectively, and at 5 years were $64 \%, 61 \%$, and $69 \%$, respectively (Figure 1). There were also no significant 
TABLE 1. Characteristics for LAS-era transplants

\begin{tabular}{|c|c|c|c|c|}
\hline Covariate & $\frac{\text { LAS transplantation only }}{(n=396)}$ & $\begin{array}{c}\text { Donor age } \\
\leq \mathbf{4 0} y \\
(n=230)\end{array}$ & $\begin{array}{c}\text { Donor age } \\
40-55 y \\
(n=108)\end{array}$ & $\begin{array}{c}\text { Donor age } \\
\geq \mathbf{5 5} \text { y } \\
(\mathbf{n}=\mathbf{5 8})\end{array}$ \\
\hline Male & $204(51.5 \%)$ & $127(55.2 \%)$ & $55(50.9 \%)$ & $22(37.9 \%)$ \\
\hline \multicolumn{5}{|l|}{ Race } \\
\hline African American & $7(1.8 \%)$ & $4(1.7 \%)$ & $2(1.9 \%)$ & $1(1.7 \%)$ \\
\hline White & $372(93.9 \%)$ & $218(94.8 \%)$ & $99(91.7 \%)$ & $55(94.8 \%)$ \\
\hline Other & $17(4.3 \%)$ & $8(3.5 \%)$ & $7(6.5 \%)$ & $2(3.4 \%)$ \\
\hline Pediatric transplant & $5(1.3 \%)$ & $5(2.2 \%)$ & $0(0.0 \%)$ & $0(0.0 \%)$ \\
\hline \multicolumn{5}{|l|}{ Primary disease } \\
\hline COPD/alpha1* & $142(35.9 \%)$ & $73(31.7 \%)$ & $37(34.3 \%)$ & $32(55.2 \%)$ \\
\hline Cystic fibrosis* & $67(16.9 \%)$ & $46(20.0 \%)$ & $18(16.7 \%)$ & $3(5.2 \%)$ \\
\hline IPF/ILD* & $135(34.1 \%)$ & $81(35.2 \%)$ & $37(34.3 \%)$ & $17(29.3 \%)$ \\
\hline Other* & $52(13.1 \%)$ & $30(13.0 \%)$ & $16(14.8 \%)$ & $6(10.3 \%)$ \\
\hline Single-lung transplant & $193(48.7 \%)$ & $105(45.7 \%)$ & $52(48.1 \%)$ & $36(62.1 \%)$ \\
\hline Recipient ever smoke, yes & $238(60.1 \%)$ & $138(60.0 \%)$ & $63(58.3 \%)$ & $37(63.8 \%)$ \\
\hline Donor male* & $266(67.2 \%)$ & $166(72.2 \%)$ & $63(58.3 \%)$ & $37(63.8 \%)$ \\
\hline Donor ever smoke, yes & $137(34.6 \%)$ & $78(33.9 \%)$ & $42(38.9 \%)$ & $17(29.3 \%)$ \\
\hline Mean PA BP $\geq 40$ & $20(5.1 \%)^{49}$ & $9(3.9 \%)^{27}$ & $8(7.4 \%)^{17}$ & $3(5.2 \%)^{5}$ \\
\hline BMI $(1,20)$ & $83(21.0 \%)^{30}$ & $52(22.6 \%)^{13}$ & $18(16.7 \%)^{10}$ & $13(22.4 \%)^{7}$ \\
\hline BMI $(20,30)$ & $238(60.1 \%)$ & $141(61.3 \%)$ & $64(59.3 \%)$ & $33(56.9 \%)$ \\
\hline BMI (30, Inf) & $45(11.4 \%)$ & $24(10.4 \%)$ & $16(14.8 \%)$ & $5(8.6 \%)$ \\
\hline LAS score $\geq 50$ & $70(17.7 \%)$ & $43(18.7 \%)$ & $20(18.5 \%)$ & $7(12.1 \%)$ \\
\hline $\mathrm{eGFR}<60$ & $30(7.6 \%)$ & $16(7.0 \%)$ & $6(5.6 \%)$ & $8(13.8 \%)$ \\
\hline Second transplantation & $7(1.8 \%)$ & $4(1.7 \%)$ & $2(1.9 \%)$ & $1(1.7 \%)$ \\
\hline Peak PGD score $=3$ & $65(16.4 \%)^{26}$ & $36(15.7 \%)^{7}$ & $20(18.5 \%)^{12}$ & $9(15.5 \%)^{7}$ \\
\hline Age at transplant* & $53.2(12.6)$ & $52.1(13.7)$ & $53.4(11.0)$ & $57.0(9.74)$ \\
\hline LAS & $42.8(18.7)$ & $43.6(20.1)$ & $42.8(17.4)$ & $39.4(15.1)$ \\
\hline Longest ischemia time & $314(146.7)^{104}$ & $311(145.5)^{62}$ & $302(155.2)^{29}$ & $347(133.8)^{13}$ \\
\hline Time on waitlist & $399(635.1)^{1}$ & $419(687.8)^{1}$ & $316(434.2)$ & $473(722.4)$ \\
\hline
\end{tabular}

All values presented as either mean (standard deviation) or $\mathrm{n}(\%)$ as appropriate. Superscript numbers indicate the number of missing values. $L A S$, Lung allocation score; $C O P D /$ alphal, chronic obstructive pulmonary disease/alphal antitrypsin deficiency; $I P F / I L D$, idiopathic pulmonary fibrosis/interstitial lung disease; $P A B P$, pulmonary artery blood pressure; $B M I$, body mass index; $e G F R$, estimated glomerular filtration rate; $P G D$, primary graft dysfunction. $*$ Rows are statistically significantly different.

differences in BOS-free or rejection-free survival between donor age groups (Figure 2). The mean incidence of peak PGD $\geq 3$ was $16 \%$ in the LAS era and not significantly different between groups.

We evaluated the effect of donor smoking on patients transplanted with lungs from donors $>50$ years of age in the LAS era. A total of 83 patients received lungs from donors $>50$ years old, and 25 of these were from donors who had smoked. The primary outcome in this subgroup analysis was 5-year survival with secondary measures, including incidence of peak PGD3 within 72 hours and prolonged time on the ventilator ( $>48$ hours). Univariate analysis showed no differences in 1- or 5-year survival between older donors who smoked versus those who did not (5-year survival $79 \%$ smokers vs $63 \%$ nonsmokers, $P=.8$; Figure E1). No significant differences between smokers and nonsmokers were found in the secondary outcomes. Incidence of peak PGD3 was $4 \%$ for smokers compared with $2 \%$ for nonsmokers $(P=.3)$. Incidence of prolonged ventilator time was $48 \%$ for smokers compared with $52 \%$ for nonsmokers $(P=.9)$.

\section{Adjusted Outcomes (LAS Era)}

Proportional hazards analysis of donor age showed no association between donor age and recipient survival or BOS $\geq 1$-free survival (Table 2). Survival and BOS $\geq 1$-free survival were negatively associated with the recipient sex being male. The flat spline curve in Figure 3 demonstrates minimal effect of donor age on survival across a wide range of ages $(P=.9)$. Similarly, no effect was noted on the composite of BOS or death, or on peak PGD3 (Figure 4). 


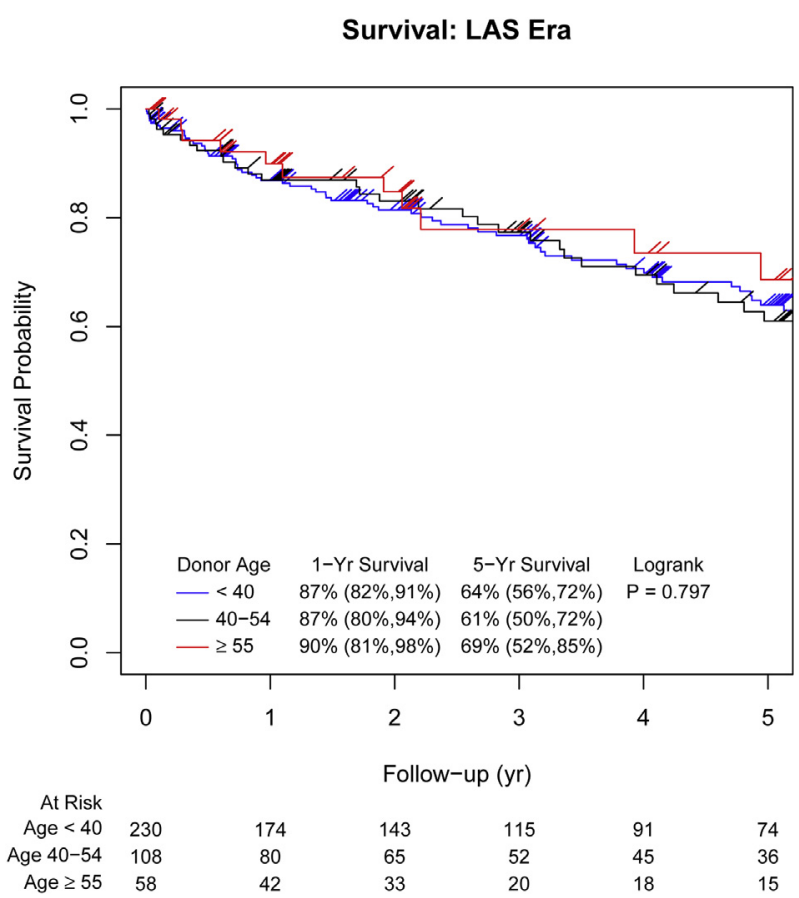

FIGURE 1. Kaplan-Meier survival curves for LAS era $(\mathrm{n}=396)$ stratified by 3 donor age groupings. $L A S$, Lung allocation score.

Twenty-one recipients received lungs from a donor older than age 60 years. Compared with a recipient of lung(s) from a 40-year-old donor, a recipient of lung(s) from a 60-year-old donor had no increased risk for peak PGD 3 within 72 hours (hazard ratio [HR], 0.97; 95\% CI, 0.44-2.12) and a negligible greater risk (HR, 1.16; $95 \%$ CI, 0.68-1.96) of the composite of BOS or death within 5 years. However, compared with a younger donor, recipients of lung(s) from a 60-year-old donor did have a
2.13 -fold $(95 \% \mathrm{CI}, 1.07-4.25)$ greater odds of ventilation $>48$ hours, 1.83 -fold $(95 \%$ CI, $0.96-3.50)$ greater odds of intensive care unit (ICU) length of stay $>7$ days, 2.03 -fold (95\% CI, 1.07-3.85) greater odds of transplant length of stay $>14$ days, and a 1.81 -fold $(95 \%$ CI, 0.92-3.57) greater odds of $>30$ hospital days within the first year. No recipient who received lungs from a donor older than 60 years of age developed a donor-transmitted malignancy.

\section{Outcomes in the Composite Cohort (pre-LAS and LAS)}

Survival endpoints were evaluated over a 10-year timeframe in the composite cohort $(\mathrm{n}=882$; Table E1). Patients who received donor lungs from donors $<40$ years old, 40-54 years old, and $\geq 55$ years old had no significant difference in the unadjusted survival $(P=.7)$ wherein 10 -year survival was $32 \%, 34 \%$, and $19 \%$, respectively (Figure 5). Adjusted proportional hazards analysis showed that donor age was not associated with 10-year survival (HR, $1.05 ; 95 \%$ CI, 0.98-1.12; $P=.2$; Table E2). Single-lung transplants were associated with an increased risk of 10-year mortality compared with bilateral lung transplants, whereas the LAS era was associated with decreased mortality.

\section{DISCUSSION}

As the number of patients with end-stage lung disease continues to increase, it is imperative to explore strategies that increase the number of suitable donor lungs. Our principal finding was that donor age did not significantly affect recipient long-term survival, either in the LAS era cohort or in the combined pre-LAS and LAS era cohort. We demonstrate not only that older-aged donors do not
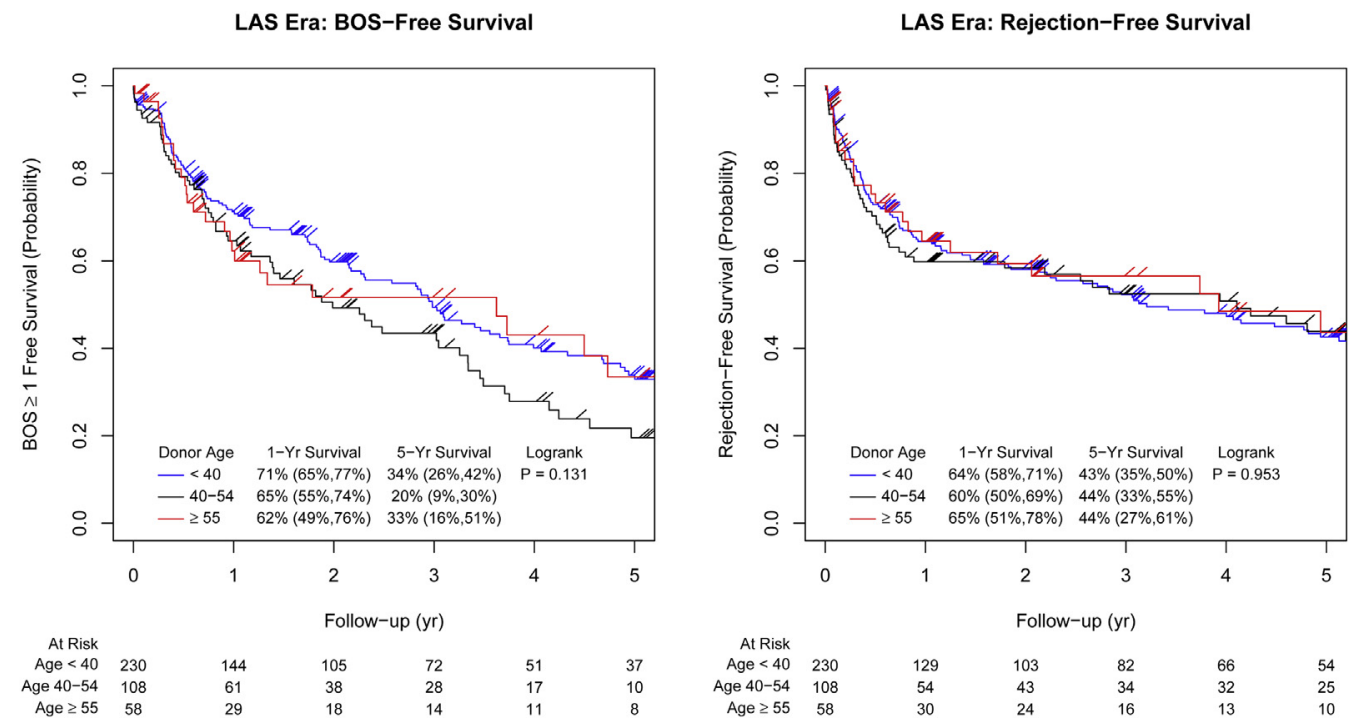

FIGURE 2. Kaplan-Meier curve for LAS-era BOS-free and rejection-free survival. LAS, Lung allocation score; BOS, bronchiolitis obliterans syndrome. 
TABLE 2. Adjusted Cox proportional HR for 5-year survival and 5-year BOS $\geq 1$-free survival; LAS-era transplants

\begin{tabular}{|c|c|c|c|}
\hline Outcome & Covariate & HR $(95 \%$ CI $)$ & $P$ value \\
\hline \multirow[t]{9}{*}{ 5-year survival } & Donor age & See splines plot & .972 \\
\hline & Single (vs bilateral) & $0.91(0.55-1.51)$ & .710 \\
\hline & Male (vs female) & $1.80(1.19-2.72)$ & .005 \\
\hline & Recipient age (per 10 years) & $1.04(0.85-1.28)$ & .704 \\
\hline & $\begin{array}{l}\text { Cystic fibrosis } \\
\text { (vs COPD/alpha1) }\end{array}$ & $1.07(0.51-2.23)$ & .867 \\
\hline & IPF (vs COPD/alpha1) & $0.69(0.41-1.17)$ & .170 \\
\hline & Other (vs COPD/alpha1) & $1.86(0.91-3.83)$ & .090 \\
\hline & LAS score (per 10 patients) & $1.05(0.96-1.15)$ & .315 \\
\hline & eGFR < 60 (vs $\geq 60)$ & $1.31(0.65-2.64)$ & .455 \\
\hline 5 -year BOS $\geq 1$ & Donor age (per 10 years) & $1.09(0.99-1.20)$ & .088 \\
\hline \multirow[t]{8}{*}{ Free survival } & Single (vs bilateral) & $1.38(0.96-1.98)$ & .083 \\
\hline & Male (vs female) & $1.46(1.09-1.97)$ & .011 \\
\hline & Recipient age (per 10 years) & $0.99(0.84-1.18)$ & .940 \\
\hline & $\begin{array}{l}\text { Cystic fibrosis } \\
\text { (vs COPD/alpha1) }\end{array}$ & $0.89(0.51-1.54)$ & .678 \\
\hline & IPF (vs COPD/alpha1) & $0.84(0.60-1.17)$ & .308 \\
\hline & Other (vs COPD/alpha1) & $1.37(0.79-2.37)$ & .257 \\
\hline & LAS score (per 10 patients) & $1.05(0.98-1.12)$ & .174 \\
\hline & eGFR < 60 (vs $\geq 60)$ & $1.26(0.80-1.99)$ & .318 \\
\hline
\end{tabular}

$H R$, Hazard ratio; $C I$, confidence interval; COPD/alphal, chronic obstructive pulmonary disease/alpha1 antitrypsin deficiency; $I P F$, idiopathic pulmonary fibrosis; $L A S$, lung allocation score; $e G F R$, estimated glomerular filtration rate; $B O S$, bronchiolitis obliterans syndrome.

contribute to decreased survival but also that younger donors do not contribute to improved survival.

Our findings support and contribute to the growing literature on the lack of effect of advanced-age donor lungs on transplant outcomes. Bittle and colleagues ${ }^{5}$ found that lungs from donors aged 55 to 64 years were not associated with decreased 1- or 3-year survival compared with younger aged donors, and only lungs from donors $>65$ years exhibited decreased survival. $^{5}$ Similarly, Hayes and colleagues $^{8}$ found that lungs from donors older than 50 did not affect recipient survival. Sommer and colleagues ${ }^{9}$ even reported equivalent survival up to 36 months after transplantation of lungs from donors aged 70 years or older. Additional studies also have shown that younger age donor lungs fail to offer a survival benefit, and older age donor lungs do not confer an increased mortality risk. ${ }^{2-4}$

Studies focusing on the rates of graft function or failure have revealed a similar pattern of noninferiority with older donor lungs. Baldwin and colleagues ${ }^{10}$ reported similar rates of graft failure at 1 year posttransplant with older donor lungs, with no association between donor age and PGD. This finding concurred with Diamond and colleagues' analysis ${ }^{11}$ of risk factors for PGD, of which age was not among them. Sommer and colleagues ${ }^{9}$ also demonstrated no difference in ventilator

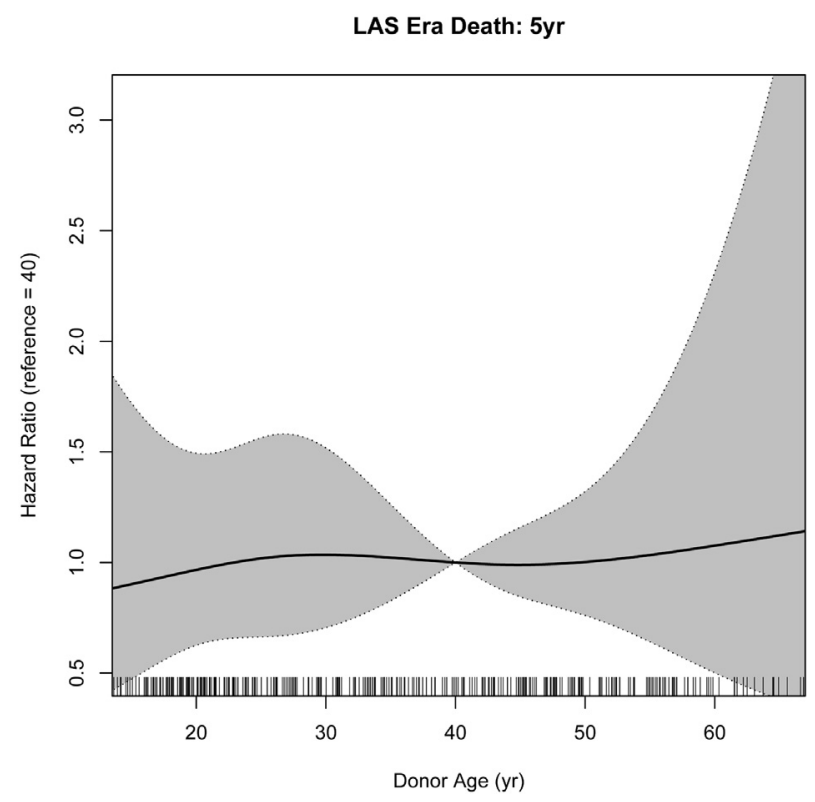

FIGURE 3. Adjusted natural cubic spline curves with $95 \%$ pointwise confidence bands for hazard ratios of primary survival outcome with respect to donor age (reference age $=40$ years; hash marks along $\mathrm{x}$-axis $=$ distribution of donor age in dataset) in the LAS era. LAS, Lung allocation score.

support or ICU length of stay with lungs from donors $\geq 70$ years of age. Other studies emphasize that it is the interaction of recipient and donor factors, including age and ischemic time (among others), and not donor age alone, that contributes to postoperative morbidity. $8,12,13$

Historically, expansion of the donor pool via the use of advanced age donor lungs has been met with resistance. Even today, there remains a perception that older donor lungs are inherently of lower quality and may yield inferior outcomes. ${ }^{1}$ Earlier studies did, indeed, paint a mixed picture of older age donor lungs, with concerns regarding their long-term durability and the development of BOS posttransplant. ${ }^{13,14}$ Our current analysis showed no difference in BOS-free or rejection-free survival across a broad spectrum of ages.

Moreover, in our institution, we offer single-lung transplants liberally to patients with favorable lung splits, older patients ( $>60$ years old), COPD without hyperinflation, advanced IPF, or any patient with elevated risk of death on the waitlist. We noted single-lung transplants were associated with a poorer 10-year survival compared with bilateral lung transplants, which is consistent with previous reports. ${ }^{15}$ Despite this, and the fact that $66 \%$ of our donors $>55$ years old were used in single-lung transplants, we still noted no survival disadvantage with the older donors. Those with cystic fibrosis, pulmonary hypertension, and those younger than 60 years of age who it was felt could tolerate a double lung transplant well, more frequently received a double lung transplant. 

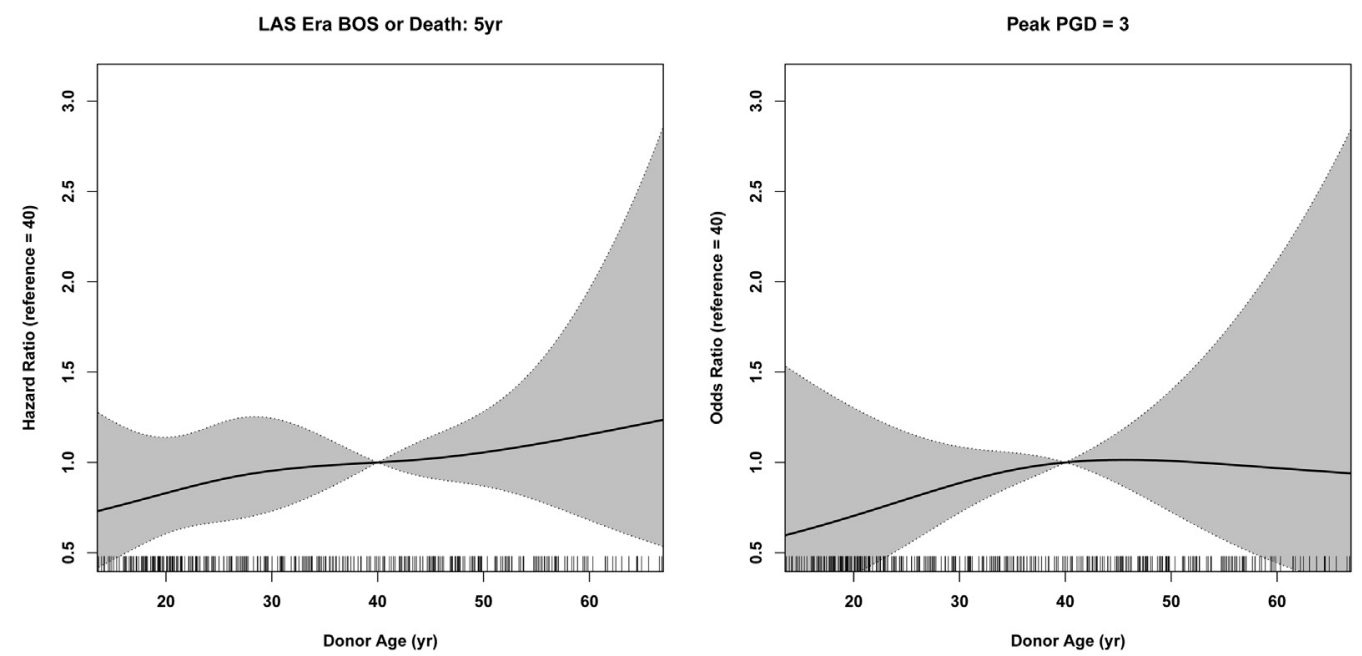

FIGURE 4. Adjusted natural cubic spline curves with $95 \%$ pointwise confidence bands for odds and hazard ratios of secondary outcomes, by donor age (reference age $=40$ years; hash marks along $\mathrm{x}$-axis $=$ distribution of donor age in dataset) in the LAS era. None of the depicted trends were statistically significant. $L A S$, Lung allocation score; BOS, bronchiolitis obliterans syndrome; $P G D$, primary graft dysfunction.

It is important to mention that donors $>60$ years of age compared with those $<40$ years old did exhibit a trend towards greater ventilator days, ICU days, and total hospital days. This finding suggests that although the older donor lungs did not result in differences in survival or early graft function, they could contribute to increased resource use after the transplant. It is conceivable that decreased elasticity of the older donors rather than reperfusion injury accounts for the delayed extubation and delayed graft function seen in these patients.

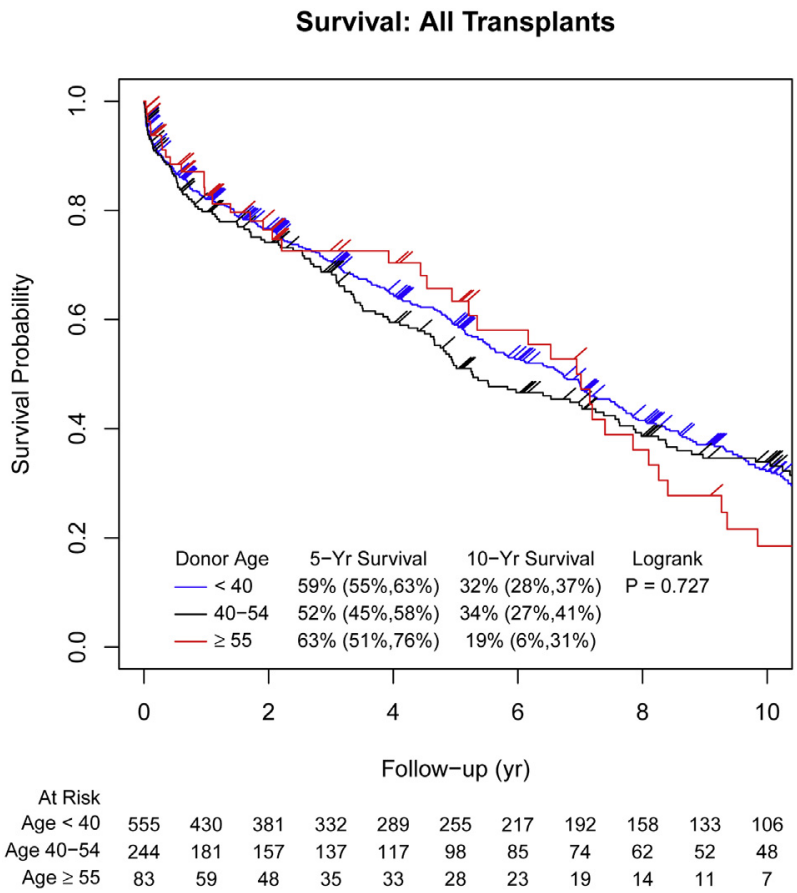

FIGURE 5. Kaplan-Meier survival curve by donor age for the combined cohort (pre-LAS and LAS).
A history of smoking in the donor is another risk factor that has been shown by others to increase the risk of PGD $^{16}$ and negatively impact long-term survival. ${ }^{11}$ The combination of smoking and older donors recently has been called into question as potentially leading to poorer transplant outcomes. ${ }^{17}$ Our analysis of the effect of donor smoking on recipients transplanted with lungs from donors $\geq 50$ years old showed no differences in survival between those who smoked versus those that did not and no statistically significant difference in the incidence of peak PGD 3 or prolonged ventilator time.

Although it does make intuitive sense to prefer a younger-aged donor for a young recipient to maximize the chance of a long-lasting graft, the consequence of delaying transplant in anticipation of a younger age donor graft (which may or may not materialize) is a legitimate concern, especially considering that the average wait-list mortality is 15 per 100 patient years. ${ }^{18}$ Hayes and colleagues $^{8}$ did note a trend towards reduced survival in younger recipients of older donors. The limited number of younger recipients transplanted with older aged donor lungs ( $>50$ years) in our cohort prevents us from commenting on a trend, or lack thereof, in this subpopulation. The concept of relative hazard between waitlist time and donor risk factors was explored in Bosner and colleagues' analysis of donor smoking, a potential risk factor for graft survival and PGD. ${ }^{16,19}$ Their study demonstrated that mortality was increased for those who waited for a nonsmoker compared with those transplanted with lungs from a smoker. ${ }^{16}$

As mentioned previously, there is still a paucity of data on the use of older age donors, and the UNOS registry confirms that it is not embraced widely. To continue to encourage the expansion of the donor pool, it is imperative that as many 


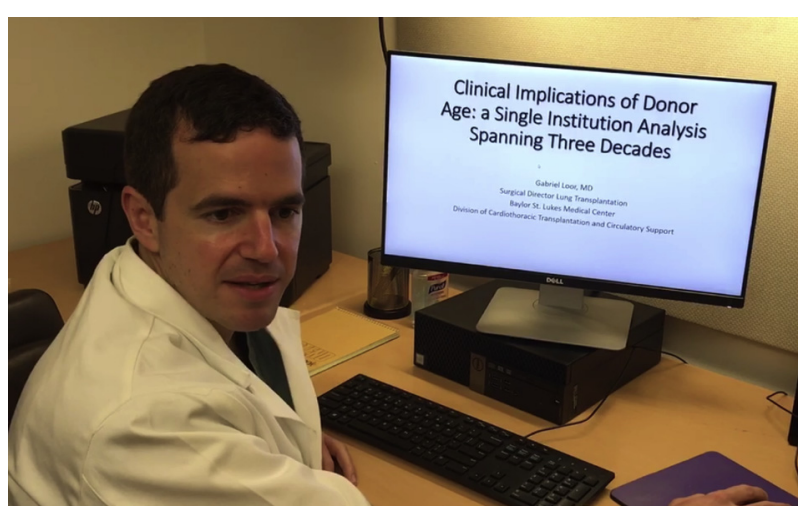

VIDEO 1. A short synopsis our study, "Clinical Implications of Donor Age: A Single-Institution Analysis Spanning 3 Decades." Video available at: http://www.jtcvsonline.org/article/S0022-5223(17)31239-4/fulltext.

careful reports as possible are available to examine the effect of donor age on post-transplant outcomes. Sommer and colleagues ${ }^{9}$ reported on 27 patients transplanted with lungs from donors older than the age of 70 years and showed no difference in 1-year survival compared with the younger age donors. Similarly, Shigemura and colleagues ${ }^{4}$ published their experience with 87 patients who received lungs from donors older than 55 years of age and found no difference in 5-year survival compared with those receiving lungs from younger donors. Although De Perrot and colleagues ${ }^{14}$ noted decreased 5- and 10-year survival for recipients transplanted with older age donors in their experience of 60 patients transplanted with donors older than the age of 60 years, they still concluded that older donors should be considered for transplant. Finally, in the most recent review on this matter, Bittle and colleagues, ${ }^{5}$ using the UNOS database, showed no difference in survival for recipients receiving lungs from donors $>55$ years of age but did note a decreased survival for recipients transplanted with lungs from donors $>65$ years of age. Their analysis also confirmed the strikingly low use of donors older than 55 years of age.

In summary, our data showed no adverse effect on survival with transplants using older age donors, and thus, we argue that an older donor may be preferable to remaining on the waiting list, especially in patients with a poor life expectancy (Video 1). However, it is possible this practice could contribute to increased hospital resource use.

\section{Limitations}

This study has the inherent limitations and biases of a single-center retrospective review. However, it includes a large number of transplants from a single institution and thus provides consistency in surgeon practice and perioperative protocols. Our database, especially in the LAS era, captured sufficient demographic and postoperative outcomes for a robust statistical analysis of the effects of donor age on recipient outcomes. Age already has been evaluated by several authors, but as a categorical variable with discrete age groupings. Our analysis also began with a priori-defined groups but went further to include continuous and nonlinear relationships between donor age and outcomes. Unfortunately, the type of preservation solution was not well documented and thus not available for analysis. However, in the LAS era our transplant center was very consistent with the use of Perfadex (Göteborg, Sweden) with prostacyclin for all donor procurements.

Finally, limited numbers of lungs from donors older than 60 years of age (only 21 transplants in our overall cohort included donor lungs from this age group, 15 of them from the LAS era) limits the degree of certainty concerning conclusions regarding lungs from donors in this age group; however, this will always be a limitation until more studies are available that support or carefully analyze the effects of increasing donor age on recipient outcomes.

\section{CONCLUSIONS}

In this large, single-center study spanning 3 decades, donor age had no effect on 5-year survival in the LAS era and no effect on 10-year survival in the combined pre-LAS and LAS era cohort. There was also no effect of donor age on short-term (PGD) or long-term (BOS) long function. There are several other important risk factors for mortality than the age of the donor and thus, donor age should be liberalized especially for those with limited life expectancy on the wait list. A crucial next step is to determine the effect on survival of remaining on the waiting list in anticipation of a younger age donor compared to undergoing transplantation with older age donor lungs.

\section{Conflict of Interest Statement}

Gabriel Loor receives grant support from Transmedics (Andover, Mass) for clinical trials related to ex vivo lung perfusion. All other authors have nothing to disclose with regard to commercial support.

We thank Mary Knatterud, $\mathrm{PhD}$, for her assistance editing the manuscript.

\section{References}

1. Valapour M, Skeans MA, Heubner BM, Smith JM, Hertz MI, Edwards LB, et al. OPTN/SRTR 2013 Annual Data Report: lung. Am J Transplant. 2015;15(suppl 2):1-28.

2. Dezza MC, Parigi PC, Corno V, Lucianetti A, Pinelli D, Zambelli M, et al. Lung transplantation with grafts from elderly donors: a single-center experience. Transplant Proc. 2010;42:1262-4.

3. Pizanis N, Heckmann J, Tsagakis K, Tossios P, Massoudy P, Wendt D, et al. Lung transplantation using donors 55 years and older: is it safe or just a way out of organ shortage? Eur J Cardiothorac Surg. 2010;38:192-7.

4. Shigemura N, Horai T, Bhama JK, D'Cunha J, Zaldonis D, Toyoda Y, et al. Lung transplantation with lungs from older donors: recipient and surgical factors affect outcomes. Transplantation. 2014;98:903-8.

5. Bittle GJ, Sanchez PG, Kon ZN, Claire Watkins A, Rajagopal K, Pierson RN, et al. The use of lung donors older than 55 years: a review of the United Network of Organ Sharing database. J Heart Lung Transplant. 2013;32:760-8. 
6. Orens JB, Boehler A, de Perrot M, Estenne M, Glanville AR, Keshavjee S, et al. A review of lung transplant donor acceptability criteria.J Heart Lung Transplant. 2003;22:1183-200.

7. Christie JD, Carby M, Bag R, Corris P, Hertz M, Weill D, et al. Report of the ISHLT Working Group on Primary Lung Graft Dysfunction part II: definition. A consensus statement of the International Society for Heart and Lung Transplantation. J Heart Lung Transplant. 2005;24:1454-9.

8. Hayes D Jr, Black SM, Tobias JD, Higgins RS, Whitson BA. Influence of donor and recipient age in lung transplantation. J Heart Lung Transplant. 2015;34:43-9.

9. Sommer W, Ius F, Salman J, Avsar M, Tudorache I, Kühn C, et al. Survival and spirometry outcomes after lung transplantation from donors aged 70 years and older. J Heart Lung Transplant. 2015;34:1325-33.

10. Baldwin MR, Peterson ER, Easthausen I, Quintanilla I, Colago E, Sonett JR, et al. Donor age and early graft failure after lung transplantation: a cohort study. Am J Transplant. 2013;13:2685-95.

11. Diamond JM, Lee JC, Kawut SM, Shah RJ, Localio AR, Bellamy SL, et al. Clinical risk factors for primary graft dysfunction after lung transplantation. Am J Respir Crit Care Med. 2013;187:527-34.

12. Meyer DM, Bennett LE, Novick RJ, Hosenpud JD. Effect of donor age and ischemic time on intermediate survival and morbidity after lung transplantation. Chest. 2000;118:1255-62.

13. Novick RJ, Bennett LE, Meyer DM, Hosenpud JD. Influence of graft ischemic time and donor age on survival after lung transplantation. J Heart Lung Transplant. 1999; 18:425-31.
14. De Perrot M, Waddell TK, Shargall Y, Pierre AF, Fadel E, Uy K, et al Impact of donors aged 60 years or more on outcome after lung transplantation: results of an 11-year single-center experience. J Thorac Cardiovasc Surg. 2007;133:525-31.

15. Thabut G, Christie JD, Ravaud P, Castier Y, Dauriat G, Jebrak G, et al. Survival after bilateral versus single-lung transplantation for idiopathic pulmonary fibrosis. Ann Intern Med. 2009;151:767-74.

16. Bonser RS, Taylor R, Collett D, Thomas HL, Dark JH, Neuberger J, et al. Effect of donor smoking on survival after lung transplantation: a cohort study of a prospective registry. Lancet. 2012;380:747-55.

17. Mulligan MJ, Sanchez PG, Evans CF, Wang Y, Kon ZN, Rajagopal K, et al. The use of extended criteria donors decreases one-year survival in high-risk lung recipients: a review of the United Network of Organ Sharing Database. $J$ Thorac Cardiovasc Surg. 2016;152:891-8.e892.

18. Valapour M, Paulson K, Smith JM, Hertz MI, Skeans MA, Heubner BM, et al OPTN/SRTR 2011 Annual Data Report: lung. Am J Transplant. 2013;13(suppl 1):149-77.

19. Berman M, Goldsmith K, Jenkins D, Sudarshan C, Catarino P, Sukumaran N et al. Comparison of outcomes from smoking and nonsmoking donors: thirteen-year experience. Ann Thorac Surg. 2010;90:1786-92.

Key Words: lung transplant, donor age, lung transplant survival, lung transplant mortality 
Survival by Donor Smoking Status

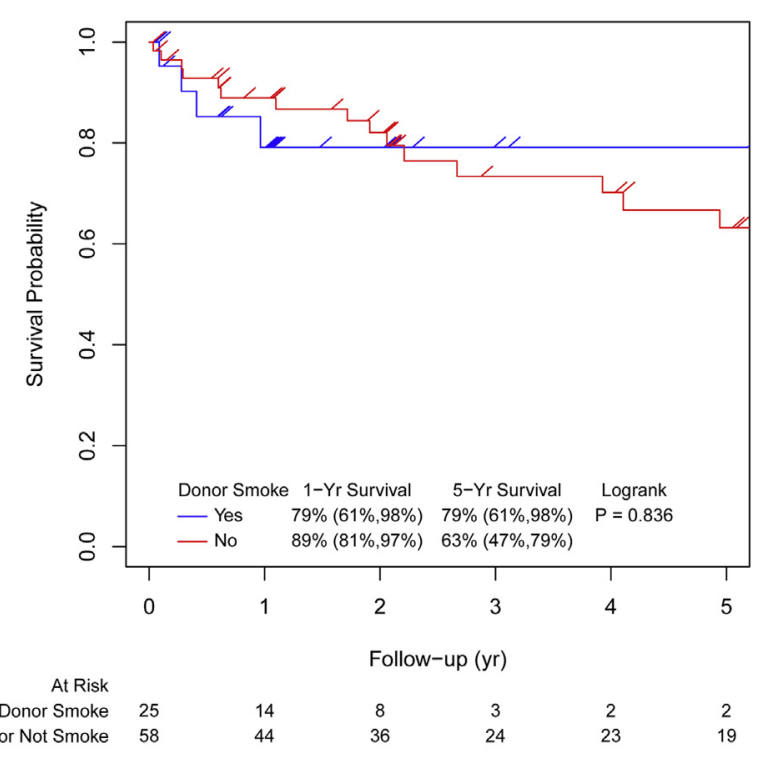

FIGURE E1. Kaplan-Meier survival curve by donor smoking status. 
TABLE E1. Characteristics for all transplants (pre-LAS and LAS era)

\begin{tabular}{|c|c|c|c|c|}
\hline Covariate & $\begin{array}{c}\text { Overall } \\
(n=882)\end{array}$ & $\begin{array}{c}\text { Donor age } \\
\leq \mathbf{4 0} \text { y } \\
(n=555)\end{array}$ & $\begin{array}{c}\text { Donor age } \\
40-55 \text { y } \\
(n=244)\end{array}$ & $\begin{array}{c}\text { Donor age } \\
\geq 55 \text { y } \\
(\mathbf{n}=\mathbf{8 3})\end{array}$ \\
\hline Male & $422(47.8 \%)$ & $280(50.5 \%)$ & $110(45.1 \%)$ & $32(38.6 \%)$ \\
\hline \multicolumn{5}{|l|}{ Race } \\
\hline African American & $18(2.0 \%)$ & $12(2.2 \%)$ & $5(2.0 \%)$ & $1(1.2 \%)$ \\
\hline White & $842(95.5 \%)$ & $530(95.5 \%)$ & $232(95.1 \%)$ & $80(96.4 \%)$ \\
\hline Other & $22(2.5 \%)$ & $13(2.3 \%)$ & $7(2.9 \%)$ & $2(2.4 \%)$ \\
\hline Pediatric transplant* & $19(2.2 \%)$ & $18(3.2 \%)$ & $1(0.4 \%)$ & $0(0.0 \%)$ \\
\hline \multicolumn{5}{|l|}{ Primary disease } \\
\hline COPD/alpha1* & $403(45.7 \%)$ & $232(41.8 \%)$ & $120(49.2 \%)$ & $51(61.4 \%)$ \\
\hline Cystic fibrosis* & $124(14.1 \%)$ & $87(15.7 \%)$ & $34(13.9 \%)$ & $3(3.6 \%)$ \\
\hline IPF/ILD* & $198(22.4 \%)$ & $122(22.0 \%)$ & $56(23.0 \%)$ & $20(24.1 \%)$ \\
\hline Other* & $157(17.8 \%)$ & $114(20.5 \%)$ & $34(13.9 \%)$ & $9(10.8 \%)$ \\
\hline Single-lung transplant* & $488(55.3 \%)$ & $289(52.1 \%)$ & $144(59.0 \%)$ & $55(66.3 \%)$ \\
\hline Recipient ever smoke, yes & $332(37.6 \%)$ & $204(36.8 \%)$ & $88(36.1 \%)$ & $40(48.2 \%)$ \\
\hline Donor male* & $533(60.4 \%)$ & $372(67.0 \%)$ & $113(46.3 \%)$ & $48(57.8 \%)$ \\
\hline Donor ever smoke, yes & $137(15.5 \%)$ & $78(14.1 \%)$ & $42(17.2 \%)$ & $17(20.5 \%)$ \\
\hline Mean PA BP $\geq 40 \dagger$ & $59(6.7 \%)$ & $41(7.4 \%)$ & $14(5.7 \%)$ & $4(4.8 \%)$ \\
\hline BMI $(1,20) \ddagger$ & $83(9.4 \%)$ & $52(9.4 \%)$ & $18(7.4 \%)$ & $13(15.7 \%)$ \\
\hline BMI $(20,30) \ddagger$ & $241(27.3 \%)$ & $144(25.9 \%)$ & $64(26.2 \%)$ & $33(39.8 \%)$ \\
\hline $\mathrm{BMI}(30$, Inf $) \ddagger$ & $45(5.1 \%)$ & $24(4.3 \%)$ & $16(6.6 \%)$ & $5(6.0 \%)$ \\
\hline LAS score $\geq 50_{\ddagger}^{\ddagger}$ & $70(7.9 \%)$ & $43(7.7 \%)$ & $20(8.2 \%)$ & $7(8.4 \%)$ \\
\hline eGFR $<60 \ddagger$ & $34(3.9 \%)$ & $19(3.4 \%)$ & $7(2.9 \%)$ & $8(9.6 \%)$ \\
\hline Second transplantation & $20(2.3 \%)$ & $13(2.3 \%)$ & $3(1.2 \%)$ & $4(4.8 \%)$ \\
\hline Peak PGD score $=3 \ddagger$ & $69(7.8 \%)$ & $40(7.2 \%)$ & $20(8.2 \%)$ & $9(10.8 \%)$ \\
\hline Age at transplant* & $50.6(13.0)$ & $49.0(14.1)$ & $52.3(10.8)$ & $56.2(9.18)$ \\
\hline $\mathrm{LAS}_{\ddagger}^{\ddagger}$ & $42.6(18.6)$ & $43.4(20.0)$ & $42.6(17.2)$ & $39.4(15.1)$ \\
\hline Longest ischemia time $\ddagger$ & $314(146.7)$ & $311(145.5)$ & $302(155.2)$ & $347(133.8)$ \\
\hline Time on wait-list & $413(638.3)$ & $432(686.5)$ & $342(461.5)$ & $473(722.4)$ \\
\hline
\end{tabular}

All values presented as either mean (standard deviation) or $\mathrm{n}(\%)$ as appropriate. COPD/alphal, Chronic obstructive pulmonary disease/alpha1 antitrypsin deficiency; $I P F / I L D$, idiopathic pulmonary fibrosis/interstitial lung disease; $P A B P$, pulmonary artery blood pressure; $B M I$, body mass index; $L A S$, lung allocation score; $e G F R$, estimated glomerular filtration rate; $P G D$, primary graft dysfunction. *Row is statistically significantly different. $\nmid 20 \%$ missing. $\ddagger$ Greater than $50 \%$ missing.

TABLE E2. Adjusted Cox proportional hazards results for 10-year survival: all transplants

\begin{tabular}{llcc}
\hline Time frame & \multicolumn{1}{c}{ Covariate } & HR $(\mathbf{9 5} \%$ CI) & $\boldsymbol{P}$ value \\
\hline $10 \mathrm{y}$ & Donor age (per 10 years) & $1.05(0.98-1.12)$ & .155 \\
& Single (vs bilateral) & $1.46(1.14-1.86)$ & .003 \\
& Male (vs female) & $1.06(0.88-1.27)$ & .549 \\
& Recipient age (per 10 years) & $1.08(0.96-1.20)$ & .206 \\
& Cystic fibrosis & $1.04(0.68-1.59)$ & .862 \\
& $\quad$ vs COPD/alpha1) & & \\
& IPF (vs COPD) & $1.15(0.90-1.48)$ & .265 \\
& Other (vs COPD) & $1.54(1.12-2.13)$ & .008 \\
& LAS era (vs pre-LAS) & $0.71(0.57-0.89)$ & .003 \\
\hline
\end{tabular}

HR, Hazard ratio; CI, confidence interval; COPD/alphal, chronic obstructive pulmonary disease/alpha1 antitrypsin deficiency; IPF, idiopathic pulmonary fibrosis; $L A S$, lung allocation score. 